Article

\title{
Synthesis of Some Monoazo Disperse Dyes Derived from Aminothienochromene
}

\author{
Saleh Mohammed Al-Mousawi ${ }^{1 *}$ and Morsy Ahmed El-Apasery ${ }^{1,2}$
}

1 Chemistry Department, Faculty of Science, Kuwait University, P.O. Box 5969, Safat 13060, Kuwait

2 Dyeing, Printing and Textile Auxiliaries Department, Textile Research Division, National Research Centre, Dokki, Giza 12622, Egypt; E-Mail: elapaserym@yahoo.com

* Author to whom correspondence should be addressed; E-Mail: saleh.almousawi@yahoo.com.

Received: 6 June 2013; in revised form: 16 July 2013 / Accepted: 17 July 2013 /

Published: 25 July 2013

\begin{abstract}
A series of azo disperse dyes based on aminothienochromene were synthesized. The fastness properties of the dyed samples were measured. Most of the dyed fabrics tested displayed excellent washing and perspiration fastness and moderate light fastness.
\end{abstract}

Keywords: polyester fabrics; disperse dyes; aminothienochromene; MORE technology

\section{Introduction}

The chemistry of aminothiophenes has received much attention due to their facile availability through the versatile Gewald synthesis [1]. The importance of azothiophene dyes is demonstrated by the high number of publications and patents [2,3] dealing in one way or another with that class of dyestuffs, noted for their highly interesting dyeing properties, namely their high degree of brightness compared with azo dyes derived from anilines [4] and their excellent shade brightness [5]. Their derivatives have long been used as intermediates in the dyestuff industry [6-9].

Aminothienochromene compounds are very useful as precursors for the synthesis of fused heterocyclic ring systems, which display an important range of biological and pharmacological activities [10-14]. In spite of the large number of reports on the utility of these compounds in the dye industry, to our knowledge, their corresponding arylazothienochromenes have never been reported as potential monoazo disperse dyes. 
In view of these findings, and in continuation of our previous studies [14] on the synthesis of a variety of aminothienochromene dyes, we now report on the successful synthesis of arylazothienochromene dyes from readily obtainable cheap starting materials and their applications as disperse dyes for dyeing polyester fabrics.

\section{Results and Discussion}

In conjunction with our interest in developing efficient routes to polyfunctional heteroaromatics as disperse dyes for polyester fabrics and/or Dye Diffusion Thermal Transfer (D2T2) printing, we report here our results on the reactivity of aminothienochromene toward some aryldiazonium chlorides. As we have placed emphasis in the last few years on adopting microwave heating as a suitable substitute to conventional heating in water or an oil baths [14], we have utilized heating in a direct beam microwave oven. We observed that by adopting Microwave Organic Reactions Enhancement (MORE) technology in the reaction of $o$-hydroxyacetophenone with ethyl cyanoacetate and elemental sulfur in the presence of diethylamine as basic catalyst with a focused microwave heating oven as an energy source at $50{ }^{\circ} \mathrm{C}$ for $4 \mathrm{~h}$, [15], 3-aminothienochromene (4) is produced in $48 \%$ yield. It is noteworthy that compound 4 was prepared in the literature in $37 \%$ yield by heating for $24 \mathrm{~h}$ utilizing morpholine or diethylamine as a basic catalyst [16].

Aminothienochromene $\mathbf{4}$ coupled with aryldiazonium chlorides to afford arylazothienochromene disperse dyes $\mathbf{7 a}-\mathbf{e}$. These compounds are most likely formed via intermediacy of $\mathbf{6}$. The structures of compounds 7a-e ( $c f$. Scheme 1) were established based on their IR spectra, which show absorption bands at $c a .3,370$ and 3,270 $\mathrm{cm}^{-1}$ for amino groups, their ${ }^{1} \mathrm{H}-\mathrm{NMR}$ spectra, which displayed signals for aromatic protons along with a broad signal at $\delta_{H} c a .7 \mathrm{ppm}\left(\mathrm{D}_{2} \mathrm{O}\right.$ exchangeable) for the two amino protons, and the absence of a thiophene $1-\mathrm{H}$ singlet at $\delta_{H} 6.86 \mathrm{ppm}$.

When the disperse dyes $7 \mathbf{a}-\mathbf{e}$ were applied to polyester fabrics at $2 \%$ (dye shade), using the high temperature dyeing method (HT) at $130{ }^{\circ} \mathrm{C}$, brown to violet color shades were obtained. The dyeing properties on the polyester fabrics were evaluated in terms of their fastness properties (e.g., fastnesses to washing, perspiration and light).

The surface color yield $K / S$ was used to explain the amount of dye absorbed on the surface of the fabric. The $K / S$ values listed in Table 1 show that arylazothienochromene disperse dyes showed the best build-up for polyester fabric and have high affinity for the polyester fabric, except for dyes $\mathbf{7 b}$ and 7d that showed poor affinity for the polyester fabric because of their lower molecular polarity.

The color of dyeing on polyester fabrics is expressed in terms of CIELAB values (Table 1), and the following CIELAB coordinates were measured: lightness $\left(L^{*}\right)$; chroma $\left(C^{*}\right)$; hue angle $(h)$ from $0^{\circ}$ to $360^{\circ}, a^{*}$, whose value represents the degree of redness (positive) and greenness (negative); and $b^{*}$, whose value represents the degree of yellowness (positive) and blueness (negative).

Hue $h$ is one of the three basic characters for color. The $h$ values in Table 1 show that almost all of the dyed polyester samples expressed the same hue except dye 7e as violet color. In general, the color hues of the disperse dye $7 \mathbf{e}$ on the polyester fabric shifted to the bluish directions; this was indicated by the negative value of $b^{*}=-11.47$ (yellow-blue axis).

The positive values of $a^{*}$ (red-green axis) indicated that the color hues of the disperse dyes $7 \mathbf{a}-\mathbf{d}$ on the polyester fabric shifted to the reddish directions. 
Scheme 1. Preparation of monoazo disperse dyes $7 \mathbf{a}-\mathbf{e}$.
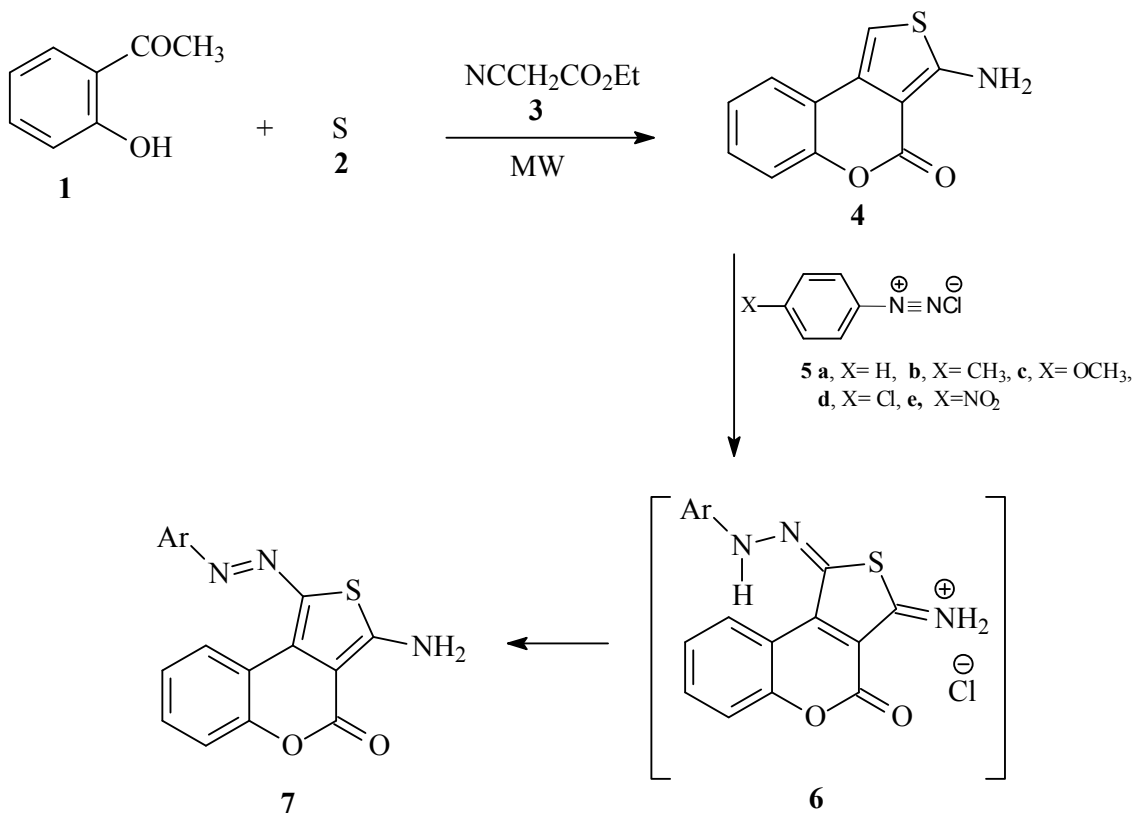<smiles>Nc1sc(/N=N/c2ccccc2)c2c1c(=O)oc1ccccc12</smiles>

$7 \mathbf{a}$<smiles>Nc1sc(/N=N/c2ccc(Cl)cc2)c2c1c(=O)oc1ccccc12</smiles>

$7 d$<smiles>Cc1ccc(/N=N/c2sc(N)c3c(=O)oc4ccccc4c23)cc1</smiles>

$7 \mathbf{b}$<smiles>Nc1sc(/N=N/c2ccccc2)c2c1c(=O)oc1ccccc12</smiles>

$7 \mathrm{c}$

Table 1. Shade and optical measurements of the azo disperse dyes on the polyester fabrics.

\begin{tabular}{cccccccc}
\hline Dye No & $\begin{array}{c}\text { Color on polyester } \\
\text { (2\% shade) }\end{array}$ & $\boldsymbol{L}^{*}$ & $\boldsymbol{a}^{*}$ & $\boldsymbol{b}^{*}$ & $\boldsymbol{C}^{*}$ & $\boldsymbol{h}^{*}$ & $\boldsymbol{K} / \boldsymbol{S}$ \\
\hline $\mathbf{7 a}$ & Orange & 58.12 & 52.91 & 64.18 & 83.18 & 50.50 & 20.66 \\
$\mathbf{7 b}$ & Brown & 59.74 & 36.18 & 42.69 & 55.96 & 49.71 & 8.55 \\
$\mathbf{7 c}$ & Dark orange & 46.13 & 48.90 & 51.72 & 71.18 & 46.60 & 28.68 \\
$\mathbf{7 d}$ & Orange & 59.26 & 52.96 & 49.46 & 72.46 & 43.04 & 11.86 \\
$\mathbf{7 e}$ & Violet & 39.61 & 44.29 & -11.47 & 45.75 & 345.48 & 8.87 \\
\hline
\end{tabular}

The visible absorption data for the synthesized dyes were measured in DMF and are listed in Table 2. The absorption maxima of the synthesized dyes ranged from $491 \mathrm{~nm}$ to $662 \mathrm{~nm}$. Within the series of azo disperse dyes investigated, the relation between the shift observed in the absorption maxima $\lambda_{\max }$ 
and polar characteristics of substituent, may be summarized as follows: (a) with the introduction of $\mathrm{OCH}_{3}, \mathrm{Cl}$ groups in the para-position of the arylhydrazono moiety, a bathochromic shift could be observed, dye 7c, and 7d $\left(\lambda_{\max } 497\right.$ and $\left.500 \mathrm{~nm}\right)$, were characterized small bathochromic shifts compared with dye 7a, $\Delta \lambda_{\max }=7$ and 10, respectively; (b) the incorporation of a $\mathrm{NO}_{2}$ group in dye 7e gave a better exhaustion and noticeable depth of color, $\Delta \lambda_{\max }=172$; (c) the bathochromic shift accompanying the substituents in the diazo component was in the following order $\mathrm{H} \rightarrow \mathrm{CH}_{3} \rightarrow \mathrm{OCH}_{3} \rightarrow \mathrm{Br} \rightarrow \mathrm{NO}_{2}$.

The physical data for the dyed fabrics given in Table 2, shows that the disperse dyeing displayed moderate fastness levels to light. Although in all the cases light fastness was poor (Table 2), the dyes 7a and 7e were marginally superior to the others, emphasizing the importance of appropriate substitutents. Attempts are in hand to improve the light fastness properties of these dyes.

In addition the results obtained showed that dyed fabrics have excellent fastness levels to washing and perspiration fastness properties that may be due to: (a) the absence of solublizing groups, which renders solubility, and wash ability of the dye-out of the fabrics, (b) the size of the dye molecule is considered relatively big, (c) the good intra-fiber diffusion of the dye molecules inside the fabrics.

Table 2. Fastness properties of monoazo disperse dyes on polyester fabrics at $2 \%$ (o.w.f).

\begin{tabular}{|c|c|c|c|c|c|c|c|c|c|c|c|}
\hline \multirow{3}{*}{$\begin{array}{c}\text { Dye } \\
\text { No }\end{array}$} & \multirow{3}{*}{$\begin{array}{c}\lambda_{\max } \\
\text { (DMF) }\end{array}$} & \multirow{2}{*}{\multicolumn{3}{|c|}{ Wash fastness }} & \multicolumn{6}{|c|}{ Perspiration fastness } & \multirow{3}{*}{$\begin{array}{l}\text { Light } \\
\text { fastness }\end{array}$} \\
\hline & & & & & \multicolumn{3}{|c|}{ Alkaline } & \multicolumn{3}{|c|}{ Acidic } & \\
\hline & & Alt & $\mathrm{SC}$ & SW & Alt & SC & SW & Alt & SC & SW & \\
\hline $7 \mathbf{a}$ & 490 & 5 & 5 & 5 & 5 & 5 & 5 & 5 & 5 & 5 & 3 \\
\hline $7 \mathbf{b}$ & 491 & 5 & 5 & 5 & 5 & 5 & 5 & 5 & 5 & 5 & 2 \\
\hline $7 c$ & 497 & 5 & $4-5$ & $4-5$ & 5 & $4-5$ & 5 & 5 & $4-5$ & 5 & 2 \\
\hline $7 d$ & 500 & 5 & 5 & 5 & 5 & 5 & 5 & 5 & 5 & 5 & $2-3$ \\
\hline $7 e$ & 662 & 5 & 5 & 5 & 5 & 5 & 5 & 5 & 5 & 5 & 3 \\
\hline
\end{tabular}

Alt = alteration; $\mathrm{SC}=$ staining on cotton; $\mathrm{SW}=$ staining on wool.

\section{Experimental}

\subsection{General}

Melting points were recorded on a Gallenkamp apparatus. IR spectra were recorded using $\mathrm{KBr}$ pellets on a JASCO FTIR-6300 FT-IR spectrophotometer. ${ }^{1} \mathrm{H}$ - and ${ }^{13} \mathrm{C}-\mathrm{NMR}$ spectra were recorded on Bruker DPX AvanceII $600 \mathrm{MHz}$ super-conducting NMR spectrometer with proton spectra measured at $600 \mathrm{MHz}$ and carbon spectra at $150 \mathrm{MHz}$, respectively. Mass spectra were measured on a high resolution GC/MS DFS-Thermo. Microanalyses were performed on Elementar-Vario Micro cube Analyzer. The dyeing of polyester fabrics were conducted using LINITEST + Laboratory High Temperature Dyeing and Fastness System (ATLAS, Lichtenstein, Germany). The colorimetric parameters of the dyed polyester fabrics were determined on a reflectance spectrophotometer (UltraScan PRO D65, HunterLab, Virginia, VA, USA).

3-Amino-4H-thieno[3,4-c]chromen-4-one (4). A mixture of $o$-hydroxyacetophenone (1, $1.86 \mathrm{~g}, 10 \mathrm{mmol})$, sulfur $(0.32 \mathrm{~g}, 10 \mathrm{mmol})$ and ethyl cyanoacetate $(1.13 \mathrm{~g}, 10 \mathrm{mmol})$, in methanol $(2 \mathrm{~mL})$ was irradiated by focused microwaves at $50{ }^{\circ} \mathrm{C}$ for $4 \mathrm{~h}$ in the presence of diethylamine $(0.73 \mathrm{~g}, 10 \mathrm{mmol})$. Completion of the reactions was monitored by TLC. The build-up of pressure in the closed reaction 
vessel was carefully monitored. After the irradiation, the reaction tube was cooled with high-pressure air through an inbuilt system in the instrument until the temperature had fallen below $50{ }^{\circ} \mathrm{C}$. The mixtures were cooled and then poured into ice-water. The solids that formed were collected by using filtration and crystallized from benzene to give compound 4 as a yellow powder $(48 \%), \mathrm{mp} 199{ }^{\circ} \mathrm{C}$ (Lit. [16] mp 197-199 ${ }^{\circ} \mathrm{C}$ ), IR (KBr): 3421, $3316\left(\mathrm{NH}_{2}\right), 1684$ (CO) $\mathrm{cm}^{-1}$. ${ }^{1} \mathrm{H}-\mathrm{NMR}$ (DMSO-d 6 ): $\delta=6.86(1 \mathrm{H}, \mathrm{s}, 1-\mathrm{H}) ; 7.17-7.21(\mathrm{~m}, 2 \mathrm{H}, 7-\mathrm{H}$ and $9-\mathrm{H}), 7.32(\mathrm{t}, 1 \mathrm{H}, J=8.0 \mathrm{~Hz}, 8-\mathrm{H})$, 7.79 (brs. $2 \mathrm{H}, \mathrm{NH}_{2}, \mathrm{D}_{2} \mathrm{O}$-exchangeable), 7.83 (d, $1 \mathrm{H}, J=6.8 \mathrm{~Hz}, 6-\mathrm{H}$ ). ${ }^{13} \mathrm{C}-\mathrm{NMR}$ (DMSO-d 6 ): $\delta=166.4$ (C-3), 158.7 (C-2), 150.7, 130.7, 129.0, 124.1, 123.7, 117.8, 116.8, 97.8, 97.3. MS (EI) $m / z=217(\mathrm{M}]^{+}$, 100), Anal. Calcd for $\mathrm{C}_{11} \mathrm{H}_{7} \mathrm{NO}_{2} \mathrm{~S}: \mathrm{C}, 60.83 ; \mathrm{H}, 3.23 ; \mathrm{N}, 6.45 ; \mathrm{S}, 14.75$. Found: C, 60.88; H, 3.31; N, 6.45; S, 14.73 .

\subsection{Reaction of Compound $\mathbf{4}$ with Aromatic Diazonium Salts}

A solution of each aryldiazonium chloride (10 mmol, prepared as described earlier [14]) at $0{ }^{\circ} \mathrm{C}$ was added to a solution of $4(10 \mathrm{mmol})$ in acetic acid $(50 \mathrm{~mL})$ containing sodium acetate $(0.60 \mathrm{~g})$. The reaction mixture was stirred at room temperature for $1 \mathrm{~h}$ and the solid product was collected by filtration and crystallized from DMF/ethanol (3:1).

3-Amino-1-(phenyldiazenyl)-4H-thieno[3,4-c]chromen-4-one (7a). Red crystals (79\%), mp $239{ }^{\circ} \mathrm{C}$ (Lit. [5] mp 238-239 ${ }^{\circ} \mathrm{C}$ ), IR (KBr): 3310 and $3164\left(\mathrm{NH}_{2}\right), 1674(\mathrm{CO}) \mathrm{cm}^{-1} .{ }^{1} \mathrm{H}-\mathrm{NMR}$ (DMSO- $d_{6}$ ): $\delta=7.02\left(\right.$ br s, $\left.2 \mathrm{H}, \mathrm{NH}_{2}\right), 7.36-7.40(\mathrm{~m}, 2 \mathrm{H}$, arom-H), $7.44(\mathrm{t}, 1 \mathrm{H}, J=8.4 \mathrm{~Hz}$, arom-H), $7.50(\mathrm{t}, 2 \mathrm{H}$, $J=7.8 \mathrm{~Hz}$, arom-H), $7.58(\mathrm{t}, 1 \mathrm{H}, J=7.2 \mathrm{~Hz}$, arom-H), 7.74 (d, 2H, $J=8.4 \mathrm{~Hz}$, arom-H), $8.83(\mathrm{~d}, 1 \mathrm{H}$, $J=9.0 \mathrm{~Hz}$, arom-H). ${ }^{13} \mathrm{C}-\mathrm{NMR}$ (DMSO-d 6 ): $\delta=169.7$ (CO), 158.7, 153.1, 152.5, 135.4, 133.5, 132.0, $129.9,129.5,129.3,125.6,122.2,117.7,117.5,100.8$. MS (EI) $\left.m / z=321(\mathrm{M}]^{+}, 100\right)$, UV/Vis at $\lambda_{\max }(\mathrm{DMF})=490 \mathrm{~nm}$. Anal. Calcd for $\mathrm{C}_{17} \mathrm{H}_{11} \mathrm{~N}_{3} \mathrm{O}_{2} \mathrm{~S}: \mathrm{C}, 63.53 ; \mathrm{H}, 3.45 ; \mathrm{N}, 13.07$; S, 9.97. Found: C, 63.22; H, 3.51; N, 12.86; S, 10.04 .

3-Amino-1-(p-tolyldiazenyl)-4H-thieno[3,4-c]chromen-4-one (7b). Brown powder (75\%), mp $293{ }^{\circ} \mathrm{C}$ (Lit. [14] mp 290-292 ${ }^{\circ} \mathrm{C}$ ), IR (KBr): 3386 and $3261\left(\mathrm{NH}_{2}\right), 1683$ (CO) cm ${ }^{-1}$; ${ }^{1} \mathrm{H}-\mathrm{NMR}$ (DMSO- $d_{6}$ ): $\delta=2.37\left(\mathrm{~s}, 3 \mathrm{H}, \mathrm{CH}_{3}\right), 6.96\left(\mathrm{brs}, 2 \mathrm{H}, \mathrm{NH}_{2}\right), 7.34-7.35(\mathrm{~m}, 3 \mathrm{H}$, arom-H), $7.41(\mathrm{t}, 1 \mathrm{H}, J=8.4 \mathrm{~Hz}$, arom-H), 7.55 (t, $1 \mathrm{H}, J=7.2 \mathrm{~Hz}$, arom-H), 7.62 (d, 2H, $J=8.4 \mathrm{~Hz}$, $p$-tolyl-H), 8.80 (d, $1 \mathrm{H}, J=7.8 \mathrm{~Hz}$, arom-H). ${ }^{13} \mathrm{C}-\mathrm{NMR}\left(\mathrm{DMSO}-d_{6}\right): \delta=168.4(\mathrm{CO}), 158.7,153.0,150.5,139.5,134.5,133.6,131.8,130.4$, 129.2, 125.5, 122.2, 117.7, 117.6, 100.5, $\left.21.4\left(\mathrm{CH}_{3}\right) . \mathrm{MS}(\mathrm{EI}) \mathrm{m} / z=335(\mathrm{M}]^{+}, 100\right)$, UV/Vis at $\lambda_{\max }(\mathrm{DMF})=319 \mathrm{~nm}$. Anal. Calcd for $\mathrm{C}_{18} \mathrm{H}_{13} \mathrm{~N}_{3} \mathrm{O}_{2} \mathrm{~S}: \mathrm{C}, 64.46 ; \mathrm{H}, 3.90 ; \mathrm{N}, 12.52 ; \mathrm{S}, 9.56$. Found: C, 64.76; H, 3.99; N, 12.63; S, 9.32.

3-Amino-1-((4-methoxyphenyl)diazenyl)-4H-thieno[3,4-c]chromen-4-one (7c). Reddish brown crystals (68\%), mp 281-283 ${ }^{\circ} \mathrm{C}$ (Lit. [14] mp 280-281 ${ }^{\circ} \mathrm{C}$ ), IR (KBr): 3380 and $3260\left(\mathrm{NH}_{2}\right), 1681(\mathrm{CO}) \mathrm{cm}^{-1}$. ${ }^{1} \mathrm{H}-\mathrm{NMR}\left(\mathrm{DMSO}-d_{6}\right): \delta=3.84\left(\mathrm{~s}, 3 \mathrm{H}, \mathrm{OCH}_{3}\right), 6.96\left(\right.$ br s, $\left.2 \mathrm{H}, \mathrm{NH}_{2}\right), 7.07(\mathrm{~d}, 2 \mathrm{H}, J=9 \mathrm{~Hz}$, p-methoxyphenyl-H), 7.32 (d, 1H, $J=8.4 \mathrm{~Hz}$, arom- $\mathrm{H}), 7.39$ (t, $1 \mathrm{H}, J=7.8 \mathrm{~Hz}$, arom-H), 7.53 (t, 1H, $J=8.4 \mathrm{~Hz}$, arom-H), 7.70 (d, 2H, $J=9 \mathrm{~Hz}, p$-methoxyphenyl-H), 8.79 (d, $1 \mathrm{H}, J=8.4 \mathrm{~Hz}$, arom-H).

${ }^{13} \mathrm{C}$ - NMR (DMSO- $\left.d_{6}\right): \delta=168.0(\mathrm{CO}), 160.7,158.8,152.9,146.6,133.8,133.3,131.6,129.1,125.5$, $\left.123.9,1117.7,117.6,115.2,100.1,55.9\left(\mathrm{OCH}_{3}\right) . \mathrm{MS}(\mathrm{EI}) m / z=351(\mathrm{M}]^{+}, 100\right)$, UV/Vis 
at $\lambda_{\max }(\mathrm{DMF})=497 \mathrm{~nm}$. Anal. Calcd for $\mathrm{C}_{18} \mathrm{H}_{13} \mathrm{~N}_{3} \mathrm{O}_{3} \mathrm{~S}: \mathrm{C}, 61.52 ; \mathrm{H}, 3.72 ; \mathrm{N}, 11.95 ; \mathrm{S}, 9.12$. Found: $61.25 ; \mathrm{H}, 3.77 ; \mathrm{N}, 11.88 ; \mathrm{S}, 8.79$.

3-Amino-1-((4-chlorophenyl)diazenyl)-4H-thieno[3,4-c]chromen-4-one (7d). Red crystals (77\%), mp $304{ }^{\circ} \mathrm{C}$ (Lit. [14] mp 300-302 ${ }^{\circ} \mathrm{C}$ ), IR (KBr): 3377 and $3270\left(\mathrm{NH}_{2}\right), 1689$ (CO) $\mathrm{cm}^{-1}$. ${ }^{1} \mathrm{H}-\mathrm{NMR}$ $\left(\right.$ DMSO- $\left.d_{6}\right): \delta=7.34(\mathrm{~d}, 1 \mathrm{H}, J=8.4 \mathrm{~Hz}$, arom-H), $7.40(\mathrm{t}, 1 \mathrm{H}, J=7.8 \mathrm{~Hz}$, arom-H), $7.54(\mathrm{~d}, 2 \mathrm{H}$, $J=9.0 \mathrm{~Hz}$, arom-H), 7.57 (t, $1 \mathrm{H}, J=7.8 \mathrm{~Hz}$, arom-H), $7.70(\mathrm{~d}, 2 \mathrm{H}, J=9.0 \mathrm{~Hz}$, arom-H), $8.78(\mathrm{~d}, 1 \mathrm{H}$, $J=8.7 \mathrm{~Hz}$, arom-H), 9.51 (br s, $\left.2 \mathrm{H}, \mathrm{NH}_{2}\right) .{ }^{13} \mathrm{C}-\mathrm{NMR}$ (DMSO- $\left.d_{6}\right): \delta=169.0(\mathrm{CO}), 158.6,153.2,151.2$, $136.2,133.4,133.3,132.2,129.9,129.3,125.6,123.6,117.7,117.4,101.2$. MS (EI) $m / z=355(\mathrm{M}]^{+}$, 100), UV/Vis at $\lambda_{\max }(\mathrm{DMF})=500 \mathrm{~nm}$. Anal. Calcd for $\mathrm{C}_{17} \mathrm{H}_{10} \mathrm{ClN}_{3} \mathrm{O}_{2} \mathrm{~S}: \mathrm{C}, 57.38 ; \mathrm{H}, 2.83 ; \mathrm{N}, 11.81 ; \mathrm{S}$, 9.01.Found: C, 57.48; H, 3.02; N, 11.97; S, 8.77.

3-Amino-1-((4-nitrophenyl)diazenyl)-4H-thieno[3,4-c]chromen-4-one (7e). Violet crystals (75\%), mp $307{ }^{\circ} \mathrm{C}$ (Lit. [14] mp 302-304 ${ }^{\circ} \mathrm{C}$ ), IR (KBr): 3373 and $3264\left(\mathrm{NH}_{2}\right), 1689$ (CO) cm ${ }^{-1} .{ }^{1} \mathrm{H}-\mathrm{NMR}$ $\left(\right.$ DMSO- $\left.d_{6}\right): \delta=7.42(\mathrm{~d}, 1 \mathrm{H}, J=7.2 \mathrm{~Hz}$, arom-H), $7.46(\mathrm{t}, 1 \mathrm{H}, J=7.6 \mathrm{~Hz}$, arom-H), $7.65(\mathrm{t}, 1 \mathrm{H}$, $J=8.8 \mathrm{~Hz}$, arom-H). $7.86\left(\mathrm{~d}, 2 \mathrm{H}, J=7.2 \mathrm{~Hz}, 4\right.$-nitrophenyl-H), 7.95 (br s, 2H, $\left.\mathrm{NH}_{2}\right), 8.32(\mathrm{~d}, 2 \mathrm{H}$, $J=8.8 \mathrm{~Hz}$, 4-nitrophenyl-H), 8.86 (d, $1 \mathrm{H}, J=8 \mathrm{~Hz}$, arom-H). MS (EI) $m / z=366$ (M] $\left.]^{+}, 100\right)$, UV/Vis at $\lambda_{\max }(\mathrm{DMF})=662 \mathrm{~nm}$. Anal. Calcd for $\mathrm{C}_{17} \mathrm{H}_{10} \mathrm{~N}_{4} \mathrm{O}_{4} \mathrm{~S}$ : C, 55.73; H, 2.75; N, 15.29; S, 8.75. Found: $55.87 ; \mathrm{H}, 2.91 ; \mathrm{N}, 15.29 ; \mathrm{S}, 8.41$.

\subsection{High Temperature Dyeing Method (HT)}

\subsubsection{Materials}

Polyester 100\% (150 $130 \mathrm{~g} / \mathrm{m}^{2}, 70 / 2$ denier) was obtained from El-Shourbagy Co., Cairo, Egypt. The fabric was treated before dyeing with a solution containing non-ionic detergent (Sera Wash M-RK, $5 \mathrm{~g} / \mathrm{L})$ and sodium carbonate $(2 \mathrm{~g} / \mathrm{L})$ in a ratio of $50: 1$ at $60{ }^{\circ} \mathrm{C}$ for $30 \mathrm{~min}$, then thoroughly washed with water and air dried at room temperature.

\subsubsection{Dyeing}

The dye bath (1:50, good to dye liquor ratio) is a sealed stainless steel dye pot of $300 \mathrm{~mL}$ capacity in the "Atlas-Germany" dyeing machine. An additional dispersing agent (Sodium lignin sulfonate) was added with a ratio to dye $1: 1$ and the $\mathrm{pH}$ of the bath was adjusted to 4.5-5 using glacial acetic acid. The dyeing was being carried out by raising the dye bath temperature from $20^{\circ} \mathrm{C}$ to $130{ }^{\circ} \mathrm{C}$ at a rate of $7{ }^{\circ} \mathrm{C} / \mathrm{min}$ and holding at this temperature for $60 \mathrm{~min}$ before rapidly cooled to $50{ }^{\circ} \mathrm{C}$. The dyed fabrics was then rinsed with cold water, reduction-cleared using sodium hydroxide $(2 \mathrm{~g} / \mathrm{L})$ and sodium hydrosulphite $(2 \mathrm{~g} / \mathrm{L})$ at $80^{\circ} \mathrm{C}$ for $30 \mathrm{~min}$ and then the dyed samples thoroughly washed and air-dried.

\subsection{Color Measurements and Analyses}

\subsubsection{Color Measurements}

The colorimetric parameters (Table 1) of the dyed polyester fabrics were determined on a reflectance spectrophotometer. The color yields of the dyed samples were determined by using the 
light reflectance technique performed on UltraScan PRO D65 UV/VIS Spectrophotometer. The color strengths, expressed as K/S values, were determined by applying the Kubelka-Mink equation as follows:

$$
\mathrm{K} / \mathrm{S}=\left[(1-\mathrm{R})^{2} / 2 \mathrm{R}\right]-\left[\left(1-\mathrm{R}_{\mathrm{o}}\right)^{2} / 2 \mathrm{R}_{\mathrm{o}}\right]
$$

where $R=$ decimal fraction of the reflectance of the dyed fabric; $R_{o}=$ decimal fraction of the reflectance of the undyed fabric; $K=$ absorption coefficient; $S=$ scattering coefficient.

\subsubsection{Fastness Testing}

Fastnesses to washing, perspiration, and light were tested according to reported methods [17].

\section{Conclusions}

In summary, a series of monoazo disperse dyes were synthesized from 3-aminothienochromene. Synthesis of the aminothienochromene in a microwave oven afforded better yield and shorter reaction times. The dyes produced in this manner were then applied to polyester fabrics using the high temperature dyeing method at $130{ }^{\circ} \mathrm{C}$. The dyed polyester fabrics, which displayed brown to violet hues, showed excellent washing and perspiration fastness and moderate light fastness.

\section{Acknowledgments}

The authors are grateful to M.H. Elnagdi for his help and valuable advices. Support of this work provided by Kuwait University through a research grant (SC 05/09) and the facilities of GF-S, supported by research grants (GS01/01), (GS01/03) and (GS01/05) are highly appreciated.

\section{Conflict of Interest}

The authors declare no conflict of interest.

\section{References}

1. Gewald, K.; Schinke, E.; Boettcher, H. Heterocycles from CH-acidic nitriles. VIII. 2-Aminothiophenes from methylene-active nitriles, carbonyl compounds, and sulfur. Chem. Ber. 1966, 99, 94-100.

2. Rangnegar, D.W.; Sabnis, R.W. Novel substituted 2-acetamido thiophene-4-styryl disperse dyes. J. Chem. Tech. Bio. 1993, 56, 401-405.

3. Hallas, G.; Choi, J.-H. Synthesis and spectral properties of azo dyes derived from 2-aminothiophenes and 2-aminothiazoles. Dyes Pigm. 1999, 42, 249-265.

4. Abd-El-Aziz, A.S.; Afifi, T.H. Novel azo disperse dyes derived from aminothiophenes: Synthesis and UV-visible studies. Dyes Pigm. 2006, 70, 8-17.

5. Fondjo, E.S.; Tsemeugne, J.; Sondengam, B.L.; Oppenlaender, T.; Wabo, H.K.; Tane, P.; Connolly, J.D.; Dehaen, W.; Rohand, T.; Kikuchi, H.; Oshima, Y. Coupling of Two Diazotized 3-Aminothieno[3,4-c]coumarins with Aromatic Amines. J. Heterocycl. Chem. 2011, 48, 1295-1301.

6. Yen, M.S.; Wang. I.J. Synthesis and absorption spectra of hetarylazo dyes derived from coupler 4-aryl-3-cyano-2-minothiophenes. Dyes Pigm. 2004, 61,243-250. 
7. Hallas, G.; Cho, J.-H. Synthesis and properties of novel aziridinyl azo dyes from 2-aminothiophenes-Part 2: Application of some disperse dyes to polyester. Dyes Pigm. 1999, 40, 119-129.

8. Bhattia, H.S.; Seshadri, S. Novel disperse dyes from benzo[b]thiophene-3(2H)-one-1,1-dioxide and ethyl benzo[ $[b]$ thien-3(2H)-ylidenecyanoacetate, $S, S$-dioxide: Synthesis and properties. Dyes Pigm. 2004, 62, 83-92.

9. Maradiya, H.R.; Patel, V.S. Thiophene based monoazo disperse dyes for polyester fabric. J. Serb. Chem. Soc. 2002, 67, 17-25.

10. Rodighiero, P.; Pastorini, G.; Dalla Via, L.; Gia, O.; Magno, S.M. Synthesis and biological activity of linear and angular 4-methoxymethylthienocoumarins and 4-acetoxymethylthienocoumarins. Farmaco 1998, 53, 313-319.

11. Manna, F.; Chimenti, F.; Bolasco, A.; Cenicola, M.L.; D'Amico, M.; Parrillo, C.; Rossi, F.; Marmo, E. Antiinflammatory, analgesic and antipyretic $\mathrm{N}$-acetyl- $\Delta 2$-pyrazolines and dihydrothienocoumarins. Eur. J. Med. Chem. 1992, 27, 633-639.

12. Al-Saleh, B.; El-Apasery, M.A. Studies with condensed aminothiophenes: Further investigation on the reactivity of condensed aminothiophenes toward electron poor olefins and acetylenes under microwave heating. J. Het. Chem. 2006, 43, 559-564.

13. Abdelkhalik, M.M.; Negm, A.M.; Elkhouly, A.I.; Elnagdi, M.H. Studies with condensed aminothiophenes: Further investigation of reactivity of aminothienocoumarines and aminothienobenzo $[h]$ coumarines toward electron-poor olefins and acetylenes. Heteroat. Chem. 2004, 15, 502-507.

14. Al-Saleh, B.; Abdelkhalik, M.M.; El-Apasery, M.A.; Elnagdi, M.H. Studies with condensed thiophenes: Reactivity of condensed aminothiophenes toward carbon and nitrogen electrophiles. J. Chem. Res. 2005, 2005, 23-26.

15. Bose, A.K.; Manhas, M.S.; Ghosh, M.; Shah, M.; Raju, V.S.; Bari, S.S.; Newaz, S.N.; Banik, B.K.; Chaudhary, A.G.; Barakat, K.J. Microwave-induced organic reaction enhancement chemistry. 2. Simplified techniques. J. Org. Chem. 1991, 56, 6968-6970.

16. Fondjo, E.S.; Doepp, D.; Henkel, G. Reactions of some anellated 2-aminothiophenes with electron poor acetylenes. Tetrahedron 2006, 62, 7121-7131.

17. Chrysler, L.P. Methods of Test for Color Fastness of Textiles and Leather, 7th ed.; Bradford: London, UK, 1990; pp. 89-94.

Sample Availability: Samples of compounds $\mathbf{4}$ and $\mathbf{7 a - e}$ are available from the authors.

(C) 2013 by the authors; licensee MDPI, Basel, Switzerland. This article is an open access article distributed under the terms and conditions of the Creative Commons Attribution license (http://creativecommons.org/licenses/by/3.0/). 